\title{
Biological Studies on Alcohol-Induced Neuronal Damage
}

\author{
Masaru Tateno, MD, PhD, \\ Toshikazu Saito, MD, PhD \\ Department of Neuropsychiatry, \\ Sapporo Medical University, \\ Sapporo, Japan
}

\begin{abstract}
Alcohol is a well-known cytotoxic agent which causes various kinds of neuronal damage. In spite of thousands of published studies, the true mechanism of alcohol-induced neuronal damage remains unclear. Neurogenesis is the generation of neurons from neural stem cells (NSCs) and occurs in predominantly two regions of the brain, the subventricular zone and the dentate gyrus of the hippocampus. NSCs are the self-renewing, multipotent precursor cells of neurons, astrocytes, and oligodendrocytes in the central nervous system. Recent studies have begun to illuminate the role of neurogenesis in the biological and cellular basis of psychiatric disorders and several clinical symptoms seen in alcoholism such as depression, cognitive impairment, underlying stress and brain atrophy have been linked to impaired neurogenesis. Heavy alcohol consumption decreases neurogenesis in animals, while in vitro studies have shown decreased generation of new neurons after alcohol exposure. These findings suggest that decreased neurogenesis is important in the pathophysiology of alcoholism. Neurogenesis can be divided into four stages; proliferation, migration, differentiation and survival. Our in vitro studies on NSCs showed that alcohol decreased neuronal differentiation at doses lower than those that affected cell survival and suggested that neuron-restrictive silencer factor, or repressor element-1 silencing transcription factor (NRSF/ REST) could be involved in alcohol-induced inhibition of neuronal differentiation. In an animal model of fetal alcohol effects behavioral symptoms improved after NSC transplantation. Neurogenesis could be the target for new strategies to treat alcohol related disorders.
\end{abstract}

KEY WORDS: Alcohol, Alcoholism, Fetal alcohol syndrome, Neural stem cell, Neurogenesis.

Psychiatry Invest 2008;5:21-27

\section{Introduction}

Alcohol is a well-known deleterious agent which damages various organs and causes serious health problems. From early times alcohol abuse has been a serious social problem. The World Health Organization estimates that worldwide about 140 million people suffer from alcoholism (http://www.who.int/en/). Despite thousands of studies designed to elucidate the underlying mechanism of alcohol dependence, its pathophysiology remains obscure. Recently, impaired neurogenesis has been considered the most plausible cause of alcohol related disorders and is attracting great attention in the field of alcohol research.

The long-standing dogma that new neurons cannot be produced in adult brains ${ }^{1}$ was overturned by breakthrough studies by Reynolds and Weiss ${ }^{2}$ in which cells from the striatum of adult mice were induced to proliferate in vitro. Subsequently, Eriksson et al. $^{3}$ using immunofluorescent labeling for bromodeoxyuridine (BrdU), demonstrated that new neurons were generated from progenitor cells in the dentate gyrus 
of the adult human brain indicating that cells in the human hippocampus retained the capacity to give rise to neurons throughout life. These concept-breaking findings triggered many more studies of neurogenesis, the phenomenon of new neuron generation in the central nervous system (CNS). Every mammal investigated to date including humans has been found to have neurogenesis in specific regions of the brain. Neural stem cells (NSCs) are the origin of newly generated neurons and their function is critical in neurogenesis. Many researchers are deeply interested in the role of NSC and in relations between changes in their function and the pathophysiology of psychiatric disorders. Emerging evidence suggests that altered NSC function plays an important role in the development of alcohol-induced neuronal damage as observed in alcoholism. ${ }^{4-7}$

This review includes a brief overview of previous studies on intracellular signaling cascades which relate to alcohol-induced cytotoxicity and summarizes accumulating evidence from studies of neurogenesis which provide new insights into the underlying mechanism of alcohol-related neuro-psychiatric disorders.

\section{Alcohol and the Intracellular Signaling Cascade}

Alcohol consumption activates the reward pathway of the brain and causes euphoria that contributes to the development of alcohol dependency. Chronic and excessive alcohol consumption damages neurons through their intracellular signal transduction pathways. Our postmortem studies using brain samples of cerebral cortex and platelets from alcoholics revealed a significant quantitative decrease of adenylyl cyclase (AC)-I and VIII. ${ }^{8}$ Activation of the G-protein-AC system generates cyclic adenosine monophosphate (AMP) (cAMP) which activates cAMP-dependent protein kinase A (A kinase). A kinase transmigrates into the nucleus, and then phosphorylates a transcription factor named cAMP-responsive element binding protein (CREB). CREB has been reported to have various target genes and to promote their transcription. ${ }^{9-11}$ The targets of CREB include neurotrophic factors such as brain-derived neurotrophic factor (BDNF), which are essential for synthesizing neurotransmitters and the molecules necessary for neuron survival. In rats, long-term alcohol consumption decreased CREB activity in the brain striatum. ${ }^{12}$ In vitro studies using cultured rat cortical neurons revealed alcohol-induced reduction of CREB activity and decreased expression of BDNF. ${ }^{13}$ These findings suggest that alcohol is a negative regulator of cAMP-CREB signal transduction acting intracellularly. Furthermore, a study using cultured neurons indicated that short-term al- cohol treatment $(0.5-2$ hours $)$ activated the cAMP system and increased expression of BDNF and other factors, whereas more prolonged treatment $(>24$ hour $)$ inhibited cAMP and decreased BDNF expression. ${ }^{14}$ BDNF and $\mathrm{CREB}$ are reported to play an essential role in the pathophysiology of depression ${ }^{15}$ which is the most common comorbidity of alcoholism. Our postmortem study showed a reduced expression of phosphorylated CREB in the orbitofrontal cortex of patients with depression. ${ }^{16}$ This correlation between an altered cAMP-CREB-BDNF cascade and depressive symptoms suggests that in the brains of alcoholics, dysfunction and loss of neurons may be the outcome of altered intracellular signals due to the suppressed CREB activity and the decreased BDNF level.

\section{Neurogenesis and Psychiatric Disorders}

The NSC is a primitive, immature cell able to self-renew and give rise to multilineage progeny of CNS cells such as neurons, astrocytes oligodendrocytes etc. ${ }^{17-19}$ NSCs reside in two discrete regions in the brain, the subventricular zone and the dentate gyrus of the hippocampus, and continue to generate new neurons throughout life. NSCs, with their multiple possibilities, have attracted considerable attention from researchers in various scientific fields. With the acceptance of neurogenesis, more studies have focused on its relation to the pathophysiology of neuro-psychiatric disorders includeing alcoholism.

The frequent co-existence of several clinical symptoms such as depression, cognitive impairment and brain atrophy in patients with alcoholism supports the hypothesis that decreased neurogenesis is related to the underlying mechanism of alcoholism. Depression is common in alcoholics $^{20}$ and psychological stressors significantly contribute to the development of alcohol-related problems. ${ }^{21,22}$ On the other hand, both physical and psychological chronic stresses are the most common animal model of depression. Stressful events elevate serum glucocorticoid levels and stimulate glutamate release in the hippocampus which inhibits the proliferation of new cells. ${ }^{23,24}$

MRI studies demonstrated a reduced hippocampus volume in patients with a long history of recurrent depressive episodes. ${ }^{25-27}$ Neuroimaging studies of alcoholics demonstrated decreased brain volumes, especially involving the hippocampus, ${ }^{28-31}$ and postmortem findings on alcoholics are consistent with the results from antemortem neuroimaging studies. ${ }^{32}$ The hippocampal volume deficit observed in animal models of alcoholism has been reported to be related to a decrease of neurons in the hippocampus. $^{33,34}$ Furthermore, several MRI studies have demonstrated that stress is related to the decreased hip- 
pocampal volumes in humans. ${ }^{35,36}$ The animal studies describing a decrease of neurons in the hippocampus after chronic stress could, at least partially, explain the lower hippocampal volume seen in patients with PTSD ${ }^{37}$ In subjects with alcoholism, depression and severe stress, a similar decrease of hippocampal volume was observed.

In regard to the treatment of depression, animal studies have demonstrated that antidepressants, ${ }^{38-40}$ mood stabilizers, ${ }^{41-43} \mathrm{BDNF}^{44,45}$ estrogen, ${ }^{46,47}$ electro convulsive treatment (ECT) ${ }^{48-50}$ physical exercise ${ }^{51-53}$ and enriched environment, ${ }^{54,55}$ all increase neurogenesis. In vivo studies by Santarelli et al. ${ }^{56}$ suggested that hippocampal neurogenesis is required to exert antidepressive effects as revealed by behavioral analysis. These findings emphasize the important role of neurogenesis in the pathophysiology of depression in several different ways. ${ }^{57-59}$

Another common clinical symptom in alcoholism is cognitive dysfunction. Severe alcohol-related dementia is known as Korsakoff's syndrome. Clinical studies on alcoholism have confirmed the effects of alcohol on cognitive functions ${ }^{60,61}$ and several animal studies have shown cognitive impairment after chronic alcohol consumption. ${ }^{62-64}$ Initially, the relationship of neurogenesis to learning attracted the attention of researchers, ${ }^{52,65}$ with the result that the connection between learning/memory and neurogenesis is now widely recognized. ${ }^{66,67}$ Predictably, dementia sufferers have a smaller brain mass than age matched controls, especially involving the hippocampus. All these findings emphasize the importance of decreased neurogenesis in the pathophysiology of alcoholism.

\section{Alcohol-Induced Neuronal Damage and Impaired Neural Stem Cell Function}

Alcohol causes various kinds of neuronal damage both to the developing and adult brain. ${ }^{68-72}$ Previously, alcohol was reported to decrease the number of neurons by increasing apoptotic cell death and reducing cell proliferation through prolongation of the cell cycle. ${ }^{73}$ More recent studies have implicated disrupted neurogenesis as a mechanism that impairs the neural network as described earlier in this review. Considering the four stages of neurogenesis; proliferation, migration, differentiation and survival, the loss of neurons may reflect not only direct damage, which decreases cell survival, but also a reduction in the number of newly generated neurons through suppression of NSC proliferation and differentiation into neuronal subtypes. The overall loss of neurons might seriously compromise the development and maintenance of the neuronal network.

A study in alcohol dependent rats demonstrated se- lective inhibition of neurogenesis in the hippocampus and a significant increase of hippocampal neurons after weeks of abstinence. ${ }^{74}$ An in vitro study using NSCs prepared from rat embryos on gestational day 13.5 in a monolayer culture ${ }^{75,76}$ showed that of the four stages of neurogenesis, differentiation was the most susceptible to alcohol effects under the employed experimental conditions. ${ }^{77}$ Furthermore, alcohol inhibited neuronal differentiation of NSCs at lower concentrations than those that impaired cell survival. ${ }^{78}$ These results suggest that alcohol effects on neuronal differentiation might occur in addition to alcoholinduced neuronal loss due to direct neuronal death and prolonged cell cycle which reduces neurons. Under the same experimental conditions the alcohol inhibition of neuronal differentiation was reduced by the treatment with neurotrophic factors such as BDNF and Insulin-like growth factor I (IGF-I) ${ }^{77}$ Further studies have suggested that these inhibitory effects of alcohol on NSC function involve extracellular regulated kinase (ERK) which is a member of the mitogenactivated protein (MAP) kinase family and plays an important role in transmission of extracellular signals such as the neurotrophic factor signaling cascade. ${ }^{79,80}$

The CNS consists of a mixture of neuronal and glial cells and it has long been controversial whether alcohol could affect the direction of NSC differentiation, that is, towards neuronal or glial cells. In some studies, the ratio of neurons to glia was unchanged even after alcohol exposure while other studies reported increased astrocytic differentiation after alcohol exposure. ${ }^{73,81,82}$ Astrocytes increase in number in response to various insults to the CNS. ${ }^{83-86}$ This reactive increase of glial cells following CNS injuries has been considered detrimental to CNS repair. However, some studies have suggested that the newly generated astrocytes in situ might release several cytokines that promote regeneration of the impaired neural network. The fact that neuronal death has often been accompanied by the generation of new neurons nearby might reflect the release of cytokines from dying neurons. ${ }^{81,82}$ Thus, it is possible that the increase of astrocytes and oligodendrocytes after alcohol exposure is a compensatory mechanism intended to repair an impaired neural network by promoting neurite outgrowth and increasing the number of newly generated neurons.

To clarify how alcohol affects the direction of NSC differentiation, in vitro studies focusing on neuron-restrictive silencer factor, or repressor element-1 silencing transcription factor (NRSF/REST) were performed. NRSF/REST is a zinc-finger transcription factor which is composed of an N-terminal repressor domain, a cluster of eight zinc fingers that functions as a DNA-binding domain, a highly basic region, a repeat-region and a $\mathrm{C}$-terminal repressor 
domain with a single zinc finger motif. ${ }^{87,88}$ NRSF/REST binds to its target which is by consensus identified as neuron-restrictive silencer element/repressor element-1 (NRSE /RE-1) ${ }^{89-92}$ NRSE/RE-1 was originally discovered in the promoters of the genes that express SCG $10^{93}$ and the type II sodium channel, ${ }^{94}$ and later shown to mediate negative regulation of neuronal genes. Through binding to NRSE/RE-1, NRSF/REST represses multiple neuronal target genes in non-neuronal tissues and also in undifferentiated neural precursors of the CNS. Its function is to control the proper timing of neuronal gene expression during neurogenesis. To understand the role of negative regulation of neuronal gene expression by NRSF/REST, we investigated the effects of alcohol on the DNA binding activity of NRSF/REST. These experiments demonstrated that alcohol enhanced the NRSF/REST binding activity to NRSE/RE-1 in a concentration-dependent manner and these concentrations inhibited neuronal differentiation without affecting cell survival. ${ }^{95}$

We then investigated the molecular mechanisms that underlie the alcohol inhibition of neuronal differentiation, specifically the expression of ERK and its phosphorylated (active) form after alcohol exposure. The treatment of NSCs with alcohol decreased phosphorylation of ERK, whereas the expression of total-ERK was not affected. To confirm the involvement of ERK in the mechanism of alcohol inhibition of neuronal differentiation, we treated NSCs with U0126, a mitogen-activated ERK kinase (MEK) inhibitor. MEK locates upstream of ERK in the MAP kinase cascade and its suppression by U0126 decreases ERK expression. U0126 treatment of NSC reduced neuronal differentiation and decreased the generation of neurons. ${ }^{95}$ Furthermore, the effect of U0126 on the DNA binding activity of NRSF was measured by treating NSCs with various concentrations of U0126, which revealed that U0126 potentiated the NRSF binding activity at the same concentration which suppressed neurogenesis.

\section{Fetal Alcohol Effects and Neural Stem Cell Transplantation}

A clinical entity called fetal alcohol effects (FAE) is a cluster of symptoms observed in children born to mothers with a history of heavy alcohol consumption during pregnancy. ${ }^{96-98}$ Fetal alcohol syndrome (FAS) is the severe form of FAE characterized by minor facial anomalies, prenatal and postnatal growth retardation, and cognitive and behavioral abnormalities. ${ }^{99,100}$ A large number of studies have demonstrated that compared to adult brain, the developing nervous system is more susceptible to ethanol toxicity. ${ }^{81,101-104}$ Although FAS/FAE is a com- pletely preventable condition, once the children develop FAE, its effects are permanent and currently there is no fundamental treatment.

Studies on neurogenesis can be divided into two main clusters, namely, those focusing on the role of neurogenesis in brain function and those aiming to use these cells to treat degenerative disorders. The candidate medical conditions for cell transplantation therapy include brain injury, ${ }^{105}$ cerebral infarction, ${ }^{106}$ Parkinson's disease, ${ }^{107}$ Huntington's disease ${ }^{108}$ and multiple sclerosis. ${ }^{109}$ However, a PubMed search failed to find any reports of cell transplantation in models of alcohol-related disorders.

We transplanted NSCs into the FAE model rat to determine the potential for repair of the disrupted neural network and to explore the possibility of regenerative stem cell therapy for FAE. ${ }^{110}$ FAE model rats were prepared by administering a high dose of alcohol $(4 \mathrm{~g} / \mathrm{kg} / \mathrm{day}, 4$ days) to pregnant rats on gestational days 10 to $13 .{ }^{111}$ NSCs prepared from 13.5-day-old healthy rat embryos were stained with fluorescein-based dye to trace their migration and labeled with [35S]-methionine to quantify their migration into the brain. These NSCs were transplanted through the tail vein one month after the prenatal alcohol exposure. Behavioral analysis using an elevated plus maze was performed 40 days after the NSC transplantation and was followed by histological analysis of the brain. Transplanted NSCs were detected in wide areas of the brain, and the number of the cells in the brains of FAE rats was higher than in the control group. Furthermore, NSC transplantation reversed the behavioral abnormalities observed in the FAE rats, such as hyperactivity and decreased anxiety. ${ }^{110}$ We concluded that NSC transplantation is a potentially promising new strategy for the treatment of alcohol-related abnormalities in FAS/ FAE.

\section{Conclusion}

Despite thousands of published studies on alcohol cytotoxicity, the true mechanism of alcohol-induced neuronal damage remains unclear. This review covers recent studies which prompt us to link neurogenesis to the pathophysiology of alcohol-related neuro-psychiatric conditions. There are a few studies which indicate an increase of hippocampal neurogenesis in certain conditions ${ }^{74,112-114}$ although most studies have demonstrated decreased neurogenesis. These conflicting results are perplexing although some do suggest the existence of factors which might be applied as novel treatment of alcohol-induced cell damage. Further studies of the mechanism of alcohol inhibition of neurogenesis are urgently needed and may open the door to new treatment strategies for alcohol-related disorders. 


\section{REFERENCES}

1. Cajal RS, May RT. Degeneration and Regeneration of the Nervous System. Vol. II. New York: Hafner Publishing, 1959, p.750.

2. Reynolds BA, Weiss S. Generation of neurons and astrocytes from isolated cells of the adult mammalian central nervous system. Science 1992;255:1707-1710.

3. Eriksson PS, Perfilieva E, Björk-Eriksson T, Alborn AM, Nordborg C, Peterson DA, et al. Neurogenesis in the adult human hippocampus. Nat Med 1998;4:1313-1317.

4. Crews FT, Miller MW, Ma W, Nixon K, Zawada WM, Zakhari S. Neural stem cells and alcohol. Alcohol Clin Exp Res 2003;27:324-335.

5. Crews FT, Nixon K. Alcohol, neural stem cells, and adult neurogenesis. Alcohol Res Health 2003;27:197-204

6. Eisch AJ, Mandyam CD. Drug dependence and addiction, II: Adult neurogenesis and drug abuse. Am J Psychiatry 2004;161:426.

7. Nixon K. Alcohol and adult neurogenesis: roles in neurodegeneration and recovery in chronic alcoholism. Hippocampus 2006;16:287-295.

8. Sohma H, Hashimoto E, Shirasaka T, Tsunematsu R, Ozawa H, Boissl $\mathrm{KW}$, et al. Quantitative reduction of type I adenylyl cyclase in human alcoholics. Biochim Biophys Acta 1999;1454:11-18.

9. Shaywitz AJ, Greenberg ME. CREB: a stimulus-induced transcription factor activated by a diverse array of extracellular signals. Annu Rev Biochem 1999;68:821-861.

10. Pandey SC. Anxiety and alcohol abuse disorders: a common role for CREB and its target, the neuropeptide Y gene. Trends Pharmacol Sci 2003;24:456-460.

11. Wand G. The anxious amygdala: CREB signaling and predisposition to anxiety and alcoholism. J Clin Invest 2005;115:2697-2699.

12. Yang X, Horn K, Wand GS. Chronic ethanol exposure impairs phosphorylation of CREB and CRE-binding activity in rat striatum. Alcohol Clin Exp Res 1998;22:382-390.

13. Sakai R, Ukai W, Sohma H, Hashimoto E, Yamamoto M, Ikeda H, et al. Attenuation of brain derived neurotrophic factor (BDNF) by ethanol and cytoprotective effect of exogenous BDNF against ethanol damage in neuronal cells. J Neural Transm 2005;112:1005-1013.

14. McGough NN, He DY, Logrip ML, Jeanblanc J, Phamluong K, Luong K, et al. RACK1 and brain-derived neurotrophic factor: a homeostatic pathway that regulates alcohol addiction. J Neurosci 2004; 24:10542-10552.

15. Duman RS. Role of neurotrophic factors in the etiology and treatment of mood disorders. Neuromolecular Med 2004;5:11-25.

16. Yamada S, Yamamoto M, Ozawa H, Riederer P, Saito T. Reduced phosphorylation of cyclic AMP-responsive element binding protein in the postmortem orbitofrontal cortex of patients with major depressive disorder. J Neural Transm 2003;110:671-680.

17. Gage FH. Mammalian neural stem cells. Science 2000;287:1433-1438.

18. Gage FH. Neurogenesis in the adult brain. J Neurosci 2002;22:612-613.

19. Gritti A, Vescovi AL, Galli R. Adult neural stem cells: plasticity and developmental potential. J Physiol Paris 2002;96:81-90.

20. Heinz A, Mann K, Weinberger DR, Goldman D. Serotonergic dysfunction, negative mood states, and response to alcohol. Alcohol Clin Exp Res 2001;25:487-495.

21. Brady KT, Sonne SC. The role of stress in alcohol use, alcoholism treatment, and relapse. Alcohol Res Health 1999;23:263-271.

22. Valdez GR, Koob GF. Allostasis and dysregulation of corticotropin-releasing factor and neuropeptide $Y$ systems: implications for the development of alcoholism. Pharmacol Biochem Behav 2004;79:671-689.

23. Gould E, Tanapat P, McEwen BS, Flügge G, Fuchs E. Proliferation of granule cell precursors in the dentate gyrus of adult monkeys is diminished by stress. Proc Natl Acad Sci U S A 1998;95:3168-3171.

24. Gould E, Tanapat P. Stress and hippocampal neurogenesis. Biol Psychiatry 1999;46:1472-1479.

25. Sheline YI, Wang PW, Gado MH, Csernansky JG, Vannier MW. Hippocampal atrophy in recurrent major depression. Proc Natl Acad Sci
U S A 1996;93:3908-3913.

26. Sheline YI, Sanghavi M, Mintun MA, Gado MH. Depression duration but not age predicts hippocampal volume loss in medically healthy women with recurrent major depression. J Neurosci 1999;19:50345043.

27. Sheline YI. 3D MRI studies of neuroanatomic changes in unipolar major depression: the role of stress and medical comorbidity. Biol Psychiatry 2000;48:791-800.

28. Jernigan TL, Schafer K, Butters N, Cermak LS. Magnetic resonance imaging of alcoholic Korsakoff patients. Neuropsychopharmacology 1991;4:175-186.

29. Laakso MP, Vaurio O, Savolainen L, Repo E, Soininen H, Aronen HJ, et al. A volumetric MRI study of the hippocampus in type 1 and 2 alcoholism. Behav Brain Res 2000;109:177-186.

30. Sullivan EV, Marsh L. Hippocampal volume deficits in alcoholic Korsakoff's syndrome. Neurology 2003;61:1716-1719.

31. Agartz I, Momenan R, Rawlings RR, Kerich MJ, Hommer DW. Hippocampal volume in patients with alcohol dependence. Arch Gen Psychiatry 1999;56:356-363.

32. Harper C, Matsumoto I. Ethanol and brain damage. Curr Opin Pharmacol 2005;5:73-78.

33. Riley JN, Walker DW. Morphological alterations in hippocampus after long-term alcohol consumption in mice. Science 1978;201:646-648.

34. Walker DW, Barnes DE, Zornetzer SF, Hunter BE, Kubanis P. Neuronal loss in hippocampus induced by prolonged ethanol consumption in rats. Science 1980;209:711-713.

35. Bremner JD, Randall P, Scott TM, Bronen RA, Seibyl JP, Southwick $\mathrm{SM}$, et al. MRI-based measurement of hippocampal volume in patients with combat-related posttraumatic stress disorder. Am J Psychiatry 1995;152:973-981.

36. Vermetten E, Vythilingam M, Southwick SM, Charney DS, Bremner JD. Long-term treatment with paroxetine increases verbal declarative memory and hippocampal volume in posttraumatic stress disorder. Biol Psychiatry 2003;54:693-702.

37. Gould E, McEwen BS, Tanapat P, Galea LA, Fuchs E. Neurogenesis in the dentate gyrus of the adult tree shrew is regulated by psychosocial stress and NMDA receptor activation. J Neurosci 1997;17:2492-2498.

38. Malberg JE, Eisch AJ, Nestler EJ, Duman RS. Chronic antidepressant treatment increases neurogenesis in adult rat hippocampus. J Neurosci 2000;20:9104-9110.

39. Manev H, Uz T, Smalheiser NR, Manev R. Antidepressants alter cell proliferation in the adult brain in vivo and in neural cultures in vitro. Eur J Pharmacol 2001;411:67-70.

40. Kodama M, Fujioka T, Duman RS. Chronic olanzapine or fluoxetine administration increases cell proliferation in hippocampus and prefrontal cortex of adult rat. Biol Psychiatry 2004;56:570-580.

41. Chen G, Rajkowska G, Du F, Seraji-Bozorgzad N, Manji HK. Enhancement of hippocampal neurogenesis by lithium. J Neurochem 2000; 75:1729-1734.

42. Son H, Yu IT, Hwang SJ, Kim JS, Lee SH, Lee YS, et al. Lithium enhances long-term potentiation independently of hippocampal neurogenesis in the rat dentate gyrus. J Neurochem 2003;85:872-881.

43. Laeng P, Pitts RL, Lemire AL, Drabik CE, Weiner A, Tang H, et al. The mood stabilizer valproic acid stimulates GABA neurogenesis from rat forebrain stem cells. J Neurochem 2004;91:238-251.

44. Pencea V, Bingaman KD, Wiegand SJ, Luskin MB. Infusion of brainderived neurotrophic factor into the lateral ventricle of the adult rat leads to new neurons in the parenchyma of the striatum, septum, thalamus, and hypothalamus. J Neurosci 2001;21:6706-6717.

45. Scharfman H, Goodman J, Macleod A, Phani S, Antonelli C, Croll S. Increased neurogenesis and the ectopic granule cells after intrahippocampal BDNF infusion in adult rats. Exp Neurol 2005;192:348-356.

46. Tanapat P, Hastings NB, Reeves AJ, Gould E. Estrogen stimulates a transient increase in the number of new neurons in the dentate gyrus of the adult female rat. J Neurosci 1999;19:5792-5801. 
47. Galea LA, Spritzer MD, Barker JM, Pawluski JL. Gonadal hormone modulation of hippocampal neurogenesis in the adult. Hippocampus 2006;16:225-232.

48. Madsen TM, Treschow A, Bengzon J, Bolwig TG, Lindvall O, Tingström A. Increased neurogenesis in a model of electroconvulsive therapy. Biol Psychiatry 2000;47:1043-1049.

49. Scott BW, Wojtowicz JM, Burnham WM. Neurogenesis in the dentate gyrus of the rat following electroconvulsive shock seizures. Exp Neurol 2000;165:231-236.

50. Hellsten J, Wennström M, Mohapel P, Ekdahl CT, Bengzon J, Tingström A. Electroconvulsive seizures increase hippocampal neurogenesis after chronic corticosterone treatment. Eur J Neurosci 2002;16:283-290.

51. van Praag H, Christie BR, Sejnowski TJ, Gage FH. Running enhances neurogenesis, learning, and long-term potentiation in mice. Proc Natl Acad Sci U S A 1999;96:13427-13431.

52. van Praag H, Kempermann G, Gage FH. Running increases cell proliferation and neurogenesis in the adult mouse dentate gyrus. Nat Neurosci 1999;2:266-270.

53. Brown J, Cooper-Kuhn CM, Kempermann G, Van Praag H, Winkler J, Gage $\mathrm{FH}$, et al. Enriched environment and physical activity stimulate hippocampal but not olfactory bulb neurogenesis. Eur J Neurosci 2003;17:2042-2046.

54. Kempermann G, Kuhn HG, Gage FH. More hippocampal neurons in adult mice living in an enriched environment. Nature 1997;386:493495 .

55. Nilsson M, Perfilieva E, Johansson U, Orwar O, Eriksson PS. Enriched environment increases neurogenesis in the adult rat dentate gyrus and improves spatial memory. J Neurobiol 1999;39:569-578.

56. Santarelli L, Saxe M, Gross C, Surget A, Battaglia F, Dulawa S, et al Requirement of hippocampal neurogenesis for the behavioral effects of antidepressants. Science 2003;301:805-809.

57. Jacobs BL, Praag H, Gage FH. Adult brain neurogenesis and psychiatry: a novel theory of depression. Mol Psychiatry 2000;5:262-269.

58. Kempermann G. Regulation of adult hippocampal neurogenesis implications for novel theories of major depression. Bipolar Disord 2002;4:17-33.

59. Kempermann G, Kronenberg G. Depressed new neurons-adult hippocampal neurogenesis and a cellular plasticity hypothesis of major depression. Biol Psychiatry 2003;54:499-503.

60. Brandt J, Butters N, Ryan C, Bayog R. Cognitive loss and recovery in long-term alcohol abusers. Arch Gen Psychiatry 1983;40:435-442.

61. Sullivan EV, Rosenbloom MJ, Pfefferbaum A. Pattern of motor and cognitive deficits in detoxified alcoholic men. Alcohol Clin Exp Res 2000;24:611-621.

62. Arendt T, Allen Y, Marchbanks RM, Schugens MM, Sinden J, Lantos PL, et al. Cholinergic system and memory in the rat: effects of chronic ethanol, embryonic basal forebrain brain transplants and excitotoxic lesions of cholinergic basal forebrain projection system. Neuroscience 1989;33:435-462.

63. Lukoyanov NV, Madeira MD, Paula-Barbosa MM. Behavioral and neuroanatomical consequences of chronic ethanol intake and withdrawal. Physiol Behav 1999;66:337-346.

64. Matthews DB, Morrow AL. Effects of acute and chronic ethanol exposure on spatial cognitive processing and hippocampal function in the rat. Hippocampus 2000;10:122-130.

65. van Praag H, Schinder AF, Christie BR, Toni N, Palmer TD, Gage FH Functional neurogenesis in the adult hippocampus. Nature 2002;415: 1030-1034.

66. Gould E, Beylin A, Tanapat P, Reeves A, Shors TJ. Learning enhances adult neurogenesis in the hippocampal formation. Nat Neurosci 1999; 2:260-265.

67. Shors TJ, Miesegaes G, Beylin A, Zhao M, Rydel T, Gould E. Neurogenesis in the adult is involved in the formation of trace memories. Nature 2001;410:372-376.

68. Hamre KM, West JR. The effects of the timing of ethanol exposure during the brain growth spurt on the number of cerebellar Purkinje and granule cell nuclear profiles. Alcohol Clin Exp Res 1993;17: 610-622.

69. Jang MH, Shin MC, Jung SB, Lee TH, Bahn GH, Kwon YK, et al. Alcohol and nicotine reduce cell proliferation and enhance apoptosis in dentate gyrus. Neuroreport 2002;13:1509-1513.

70. Miller MW. Limited ethanol exposure selectively alters the proliferation of precursor cells in the cerebral cortex. Alcohol Clin Exp Res 1996;20:139-143.

71. Nixon K, Crews FT. Binge ethanol exposure decreases neurogenesis in adult rat hippocampus. J Neurochem 2002;83:1087-1093.

72. Pierce DR, Serbus DC, Light KE. Intragastric intubation of alcohol during postnatal development of rats results in selective cell loss in the cerebellum. Alcohol Clin Exp Res 1993;17:1275-1280.

73. Jacobs JS, Miller MW. Proliferation and death of cultured fetal neocortical neurons: effects of ethanol on the dynamics of cell growth. J Neurocytol 2001;30:391-401.

74. Nixon K, Crews FT. Temporally specific burst in cell proliferation increases hippocampal neurogenesis in protracted abstinence from alcohol. J Neurosci 2004;24:9714-9722.

75. Johe KK, Hazel TG, Muller T, Dugich-Djordjevic MM, McKay RD. Single factors direct the differentiation of stem cells from the fetal and adult central nervous system. Genes Dev 1996;10:3129-3140.

76. Rajan P, McKay RD. Multiple routes to astrocytic differentiation in the CNS. J Neurosci 1998;18:3620-3629.

77. Tateno M, Ukai W, Ozawa H, Yamamoto M, Toki S, Ikeda H, et al. Ethanol inhibition of neural stem cell differentiation is reduced by neurotrophic factors. Alcohol Clin Exp Res 2004;28:134S-138S.

78. Tateno M, Ukai W, Yamamoto M, Hashimoto E, Ikeda H, Saito T. The effect of ethanol on cell fate determination of neural stem cells. Alcohol Clin Exp Res 2005;29:225S-229S

79. Marshall CJ. Specificity of receptor tyrosine kinase signaling: transient versus sustained extracellular signal-regulated kinase activation. Cell 1995;80:179-185.

80. Giovannini MG. The role of the extracellular signal-regulated kinase pathway in memory encoding. Rev Neurosci 2006;17:619-634.

81. Miller MW. Effects of prenatal exposure to ethanol on callosal projection neurons in rat somatosensory cortex. Brain Res 1997;766:121128.

82. Zharkovsky T, Kaasik A, Jaako K, Zharkovsky A. Neurodegeneration and production of the new cells in the dentate gyrus of juvenile rat hippocampus after a single administration of ethanol. Brain Res 2003; 978:115-123.

83. Ridet JL, Malhotra SK, Privat A, Gage FH. Reactive astrocytes: cellular and molecular cues to biological function. Trends Neurosci 1997; 20:570-577.

84. Eng LF, Ghirnikar RS. GFAP and astrogliosis. Brain Pathol 1994;4: 229-237.

85. Mathewson AJ, Berry M. Observations on the astrocyte response to a cerebral stab wound in adult rats. Brain Res 1985;327:61-69.

86. Tagliaferro P, Vega MD, Evrard SG, Ramos AJ, Brusco A. Alcohol exposure during adulthood induces neuronal and astroglial alterations in the hippocampal CA-1 area. Ann N Y Acad Sci 2002;965:334-342.

87. Tapia-Ramírez J, Eggen BJ, Peral-Rubio MJ, Toledo-Aral JJ, Mandel G. A single zinc finger motif in the silencing factor REST represses the neural-specific type II sodium channel promoter. Proc Natl Acad Sci U S A 1997;94:1177-1182.

88. Thiel G, Lietz M, Leichter M. Regulation of neuronal gene expression. Naturwissenschaften 1999;86:1-7.

89. Mori N, Schoenherr C, Vandenbergh DJ, Anderson DJ. A common silencer element in the SCG10 and type II Na + channel genes binds a factor present in nonneuronal cells but not in neuronal cells. Neuron 1992;9:45-54.

90. Kraner SD, Chong JA, Tsay HJ, Mandel G. Silencing the type II sodium channel gene: a model for neural-specific gene regulation. Neuron 
1992;9:37-44

91. Schoenherr CJ, Anderson DJ. The neuron-restrictive silencer factor (NRSF) : a coordinate repressor of multiple neuron-specific genes. Science 1995;267:1360-1363.

92. Chong JA, Tapia-Ramírez J, Kim S, Toledo-Aral JJ, Zheng Y, Boutros MC, et al. REST: a mammalian silencer protein that restricts sodium channel gene expression to neurons. Cell 1995;80:949-957.

93. Mori N, Stein R, Sigmund O, Anderson DJ. A cell type-preferred silencer element that controls the neural-specific expression of the SCG10 gene. Neuron 1990;4:583-594.

94. Maue RA, Kraner SD, Goodman RH, Mandel G. Neuron-specific expression of the rat brain type II sodium channel gene is directed by upstream regulatory elements. Neuron 1990;4:223-231.

95. Tateno M, Ukai W, Hashimoto E, Ikeda H, Saito T. Implication of increased NRSF/REST binding activity in the mechanism of ethanol inhibition of neuronal differentiation. J Neural Transm 2006;113:283-293.

96. Famy C, Streissguth AP, Unis AS. Mental illness in adults with fetal alcohol syndrome or fetal alcohol effects. Am J Psychiatry 1998;155: 552-554.

97. Ikonomidou C, Bittigau P, Ishimaru MJ, Wozniak DF, Koch C, Genz $\mathrm{K}$, et al. Ethanol-induced apoptotic neurodegeneration and fetal alcohol syndrome. Science 2000;287:1056-1060.

98. Sokol RJ, Delaney-Black V, Nordstrom B. Fetal alcohol spectrum disorder. JAMA 2003;290:2996-2999.

99. Jones KL, Smith DW. Recognition of the fetal alcohol syndrome in early infancy. Lancet 1973;2:999-1001.

100. Clarren SK, Smith DW. The fetal alcohol syndrome. N Engl J Med 1978;298:1063-1067.

101. Maier SE, Cramer JA, West JR, Sohrabji F. Alcohol exposure during the first two trimesters equivalent alters granule cell number and neurotrophin expression in the developing rat olfactory bulb. J Neurobiol 1999;41:414-423.

102. White AM, Swartzwelder HS. Hippocampal function during adolescence: a unique target of ethanol effects. Ann N Y Acad Sci 2004;1021: 206-220.

103. West JR, Hamre KM, Cassell MD. Effects of ethanol exposure during the third trimester equivalent on neuron number in rat hippocampus and dentate gyrus. Alcohol Clin Exp Res 1986;10:190-197.
104. Ieraci A, Herrera DG. Single alcohol exposure in early life damages hippocampal stem/progenitor cells and reduces adult neurogenesis. Neurobiol Dis 2007;26:597-605.

105. Lu D, Mahmood A, Wang L, Li Y, Lu M, Chopp M. Adult bone marrow stromal cells administered intravenously to rats after traumatic brain injury migrate into brain and improve neurological outcome. Neuroreport 2001;12:559-563.

106. Chen J, Li Y, Katakowski M, Chen X, Wang L, Lu D, et al. Intravenous bone marrow stromal cell therapy reduces apoptosis and promotes endogenous cell proliferation after stroke in female rat. $\mathrm{J}$ Neurosci Res 2003;73:778-786.

107. Brederlau A, Correia AS, Anisimov SV, Elmi M, Paul G, Roybon L, et al. Transplantation of human embryonic stem cell-derived cells to a rat model of Parkinson's disease: effect of in vitro differentiation on graft survival and teratoma formation. Stem Cells 2006;24:1433-1440.

108. Lee ST, Chu K, Park JE, Lee K, Kang L, Kim SU, et al. Intravenous administration of human neural stem cells induces functional recovery in Huntington's disease rat model. Neurosci Res 2005;52:243-249.

109. Pluchino S, Quattrini A, Brambilla E, Gritti A, Salani G, Dina G, et al. Injection of adult neurospheres induces recovery in a chronic model of multiple sclerosis. Nature 2003;422:688-694.

110. Yoshinaga T, Hashimoto E, Ukai W, Toki S, Saito S, Saito T. Neural stem cell transplantation in a model of fetal alcohol effects. J Neural Transm Suppl 2007; (72):331-337.

111. Endres M, Toso L, Roberson R, Park J, Abebe D, Poggi S, et al. Prevention of alcohol-induced developmental delays and learning abnormalities in a model of fetal alcohol syndrome. Am J Obstet Gyn-ecol 2005;193:1028-1034.

112. Pawlak R, Skrzypiec A, Sulkowski S, Buczko W. Ethanol-induced neurotoxicity is counterbalanced by increased cell proliferation in mouse dentate gyrus. Neurosci Lett 2002;327:83-86.

113. Rice AC, Bullock MR, Shelton KL. Chronic ethanol consumption transiently reduces adult neural progenitor cell proliferation. Brain Res 2004;1011:94-98.

114. Aberg E, Hofstetter CP, Olson L, Brené S. Moderate ethanol consumption increases hippocampal cell proliferation and neurogenesis in the adult mouse. Int J Neuropsychopharmacol 2005;8:557-567. 